\title{
RETÓRICA PUBLICITARIA E IDENTIDAD CULTURAL. ESTUDIO COMPARATIVO DE LOS SPOTS DE GADIS Y CAMPOFRÍO
}

\author{
M. ángeles RODRÍGUEZ FONTELA \\ Universidad de Santiago de Compostela
}

$\mathrm{L}$ a retórica, una de las disciplinas con más tradición en el estudio del discurso ${ }^{1}$, ha visto incrementada su operatividad instrumental en la producción y análisis textual con la emergencia contemporánea de nuevos códigos y medios de comunicación, sobre todo con aquellos dotados de un gran poder de seducción. La publicidad, que trataremos en este ensayo y que, como bien sabemos, atiende fundamentalmente a objetivos comerciales, es particularmente seductora porque las imágenes visuales y sonoras que nos llegan desde ese medio ${ }^{2}$, para lograr aquellos objetivos, sirven al imperativo de la apariencia, de lo manifiesto en lo más superficial y anulan en el receptor el impulso interpretativo que busca la verdad ( $c f r$. Baudrillard, 2000: 55). En este sentido, la publicidad se aproxima a la concepción de medio caliente de Marshall McLuhan (1996 [1964]: 43-52) en cuanto saturado de información y con pocas lagunas para el espíritu crítico del espectador. Como cualquier ser seductor, la publicidad invita a la rendición, no a la reflexión ${ }^{3}$.

\footnotetext{
${ }^{1}$ En el presente trabajo entenderemos la palabra discurso en las acepciones que para tal término recoge Helena Beristáin (1985: 153-154) en su Diccionario de Poética y Retórica, especialmente «lenguaje puesto en acción» o «cualquier proceso semiótico no lingüístico (filme, ritual, etcétera)». Estas dos acepciones son especialmente pertinentes en retórica y publicidad.

${ }^{2}$ No entraremos en el estatuto ontológico de la publicidad -arte, medio, discurso, etc.-, pues de todo participa. Si aquí consideramos la publicidad como medio -en cuanto canaliza mensajes comerciales, fundamentalmente- es en ese sentido de mise en abyme con que McLuhan considera los medios (1996 [1964]: 29). Para McLuhan, cualquier extensión o tecnología nueva hace que el medio antiguo se convierta en mensaje: el medio es el mensaje. Así lo aplicamos a la publicidad: el medio publicitario es, a su vez, mensaje de otros medios: la prensa escrita, la radio, la televisión, internet, etc.

${ }^{3}$ Uno de los factores que contribuyen al impacto seductor de la publicidad y a su recepción acrítica es la urgencia y el fast thinking que imponen determinados medios, fundamentalmente la televisión. El problema afecta no solo a los receptores, sino también a los emisores. Hablando precisamente de los fast thinkers televisivos, Pierre Bourdieu se pregunta y responde: «cómo consiguen pensar en unas condiciones en las que nadie es capaz de hacerlo. La respuesta, me parece, es que piensan mediante "ideas preconcebidas", es decir, mediante "tópicos". Las "ideas preconcebidas" de que habla Flaubert son ideas que todo el mundo ha recibido, porque flotan en el ambiente, banales, convencionales, corrientes; por eso, el problema de la recepción no se plantea: no pueden recibirse porque ya han sido recibidas» (Bourdieu, 1997 [1996]: 39).
} 
Esta naturaleza seductora de la publicidad obedece a estrategias puestas en práctica ya en la antigüedad por los maestros de retórica en los ámbitos comunicativos de aquella época -judiciales, políticos, pero también mercantiles-. La verosimilitud -la apariencia de verdad- y la persuasión ${ }^{4}$ -dirigida en gran medida a las emociones de un auditorio específico ( $c f r$. el concepto de target en publicidad) - tenían como objetivo, igual que ahora en publicidad, la movilización del auditorio en una determinada dirección.

Así pues, fiel a la verosimilitud y atenta sobre todo a las emociones del público ${ }^{5}$, la retórica se especializó en crear mensajes revestidos de las mejores galas de la poética con el fin de llevar al huerto a una audiencia rendida. No por casualidad uno de los padres de la antigua retórica, Empédocles de Agrigento, tenía fama de mago y poeta, y no por casualidad se eligió la figura del Hércules gálico ${ }^{6}$ para ilustrar la retórica en la Biblioteca de El Escorial. Las cadenillas de oro -metáfora de las palabras seductoras que salen de la boca del héroe griego- son armas más poderosas que las que sostienen sus manos: no vencen, ni convencen; arrastran a la multitud que le sigue fascinada ${ }^{7}$.

También el Hércules gálico publicitario persuade y seduce con la belleza del mensaje y con la apelación a los lugares comunes y a los valores que rigen en una sociedad determinada. Nunca como en estos momentos se aprecia tanto la funcionalidad estética de los anuncios, presente en las palabras, pero sobre todo en las imágenes. La descontextualización del producto publicitado, lograda mediante diversos recursos retóricos, alcanza la ocultación máxima de dicho producto en la publicidad de las últimas décadas de manos de directores de cine que logran en la transmedialidad ${ }^{8}$ cine-publicidad altas cotas de belleza. A la desautomatización e invisibilización del producto publicitado con fines estéticos se añade, la belleza de la composición icono-plástica, el refuerzo emocional de la música -no exenta

\footnotetext{
${ }^{4}$ Recordemos que la retórica fue definida en la antigüedad como «arte de persuadir». A Perelman, uno de los padres de la nueva retórica (1989: 65-70) se debe la distinción entre persuadir y convencer en las tres direcciones semánticas que apreciamos en la publicidad. Para Perelman, persuadir es más que convencer precisamente porque atiende a los sentimientos y emociones (primer valor semántico del término) de un auditorio específico (segundo valor) con el fin de que se actúe en una determinada dirección (tercer valor). Recuérdese a este respecto que ya Aristóteles en su Retórica dedicó el segundo de los libros de esta obra a estudiar los sentimientos humanos cuya consideración supone en el estagirita un factor a tener en cuenta en la necesaria disposición del discurso para un auditorio particular.

${ }^{5}$ El objetivo emocional de la publicidad existió desde el principio pero se ha hecho patente para creativos y estudiosos por razones varias a partir de la década de los setenta. Cfr. León Sáez de Ybarra (2007: 16).

${ }^{6}$ Versión lucianesca de Hércules - conocida en el siglo XVI en Europa a partir de la traducción que Erasmo hizo de la obra del escritor de Samosata- que debe su condición persuasiva y su representación (con piel de león, arco y maza) a la identificación con el dios galo Ogmios. En la Biblioteca de El Escorial comparte con otra imagen pictórica -la defensa que Cicerón hizo de Cayo Rabirio- la ilustración de la retórica en el cuadro general de las artes liberales.

${ }^{7}$ La ausencia de espíritu crítico, más propio de un discurso convincente que persuasivo, es lo que explica, según Mario Vargas Llosa, el dominio de la publicidad en la cultura actual: «El vacío dejado por la desaparición de la crítica ha permitido que, insensiblemente, lo haya llenado la publicidad, convirtiéndose ésta en nuestros días no sólo en parte constitutiva de la vida cultural sino en su vector determinante. La publicidad ejerce un magisterio decisivo en los gustos, la sensibilidad, la imaginación y las costumbres. La función que antes tenían, en este ámbito, los sistemas filosóficos, las creencias religiosas, las ideologías y doctrinas y aquellos mentores que en Francia se conocían como los mandarines de una época, hoy la cumplen los anónimos “creativos" de las agencias publicitarias» (Vargas Llosa, 2012: 38).

8 Concepto que con otros, como multimedialidad, intermedialidad, remediación, etc., representa la tendencia a la hibridación de códigos, artes y medios de la posmodernidad. Sometidos en estas décadas a debate teórico en aras de una definición conceptual y de un conocimiento más preciso de los procesos de hibridación en ellos implicados, elegimos en este punto el concepto de transmedialidad porque nos parece el más cercano a la idea que intentamos transmitir: el paso de contenidos y formas de un medio a otro - cine > publicidad-. Cfr. especialmente Kattenbelt (2008: 19-29).
} 
ella misma de belleza-, la riqueza de interacción de códigos en la composición y estructura del anuncio (dispositio retórica), los recursos poético-retóricos del mensaje lingüístico, y el poder comunicativo y teatral de los gestos y movimientos de los actores.

Pero estos recursos empleados en publicidad con funcionalidad estética y seductora no lograrían su propósito persuasivo si no estuvieran vinculados a los valores culturales ${ }^{9}$ de una comunidad. Empleamos el término 'cultura' en el sentido que le atribuyen los Culture Studies, especialmente Raymond Williams ${ }^{10}$ : no solo referida a las manifestaciones artísticas y procesos de conocimiento reservados tradicionalmente a las clases elevadas, sino a cualquier manifestación que muestre el modo de ser, de vivir y de actuar de cualquier sector de la población (clase, grupo, nacionalidad, etc.).

Con esta ampliación semántica, los valores culturales que una sociedad reconoce como propios, que reflejan su identidad, están presentes en las costumbres y modos de vida, en las actitudes vitales y en las creaciones y expresiones humanas de amplio espectro que representan esos valores y actitudes. La publicidad mantiene estrechos vínculos con esos valores - promocionándolos, desviándolos, simplificándolos, banalizándolos, creándolos y recreándolos-; con la jerarquía de los valores (Perelman, 1989: 131-144) -más importante aún que los valores, según Perelman (141)-, bajo los cuales se advierten los lugares comunes ${ }^{11}$, esas «premisas de carácter general que permiten fundamentar los valores y las jerarquías y que Aristóteles estudia entre los lugares de accidente» (145). Esas premisas, «sobreentendidas con frecuencia, que intervienen para justificar la mayoría de nuestras elecciones» (146) constituyen, juntamente con otros argumentos, codificados por la antigua y nueva retórica y en gran medida falaces, el entramado persuasivo que sostiene la publicidad.

Hemos elegido para nuestro estudio los anuncios de Gadis y de Campofrío, dos empresas relacionadas con el mundo de la alimentación. Gadisa (Gallega Distribuidora Alimentos) es una empresa de radicación y capital gallego que, en colaboración con la agencia publicitaria BAP \& Conde, ha emitido desde el 2007 hasta la actualidad una serie de anuncios que han cosechado éxitos notables de audiencia y amplio reconocimiento dentro del ámbito creativo publicitario" ${ }^{12}$ El eslogan "Vivamos como galegos" ha constituido nexo de unión de todas las campañas y ha sido enriquecido sucesivamente con fórmulas extraídas de modismos propios del idioma en los que se pretende

\footnotetext{
9 Teniendo en cuenta la ampliación semántica del término 'cultura' - no solo arte y conocimiento sino modos de vida y actitudes vitales- propiciada por los Estudios Culturales enfatizamos en aquel término la acepción semiótica que defiende Clifford Geertz (2000 [1973]: 20) en estos términos: «Creyendo con Max Weber que el hombre es un animal inserto en tramas de significación que él mismo ha tejido, considero que la cultura es esa urdimbre y que el análisis de la cultura ha de ser por lo tanto no una ciencia experimental en busca de leyes, sino una ciencia interpretativa en busca de significaciones». La naturaleza semiótica de la publicidad, enriquece en este sentido, el potencial cultural de sus mensajes. Sobre la consideración de la 'cultura' como sistema significante, cfr. también Raymond Williams (1982 [1981]: 194-196). ${ }^{10} \mathrm{Cfr}$. "Where culture meant a state or habit of the mind, or the body of intellectual and moral activities, it means now, also, a whole way of life." (Williams, 1976 [1958]: 18).

${ }^{11}$ En este trabajo seguiremos el esquema de lugares comunes (de cantidad, cualidad, orden, esencia) que presenta Perelman (1989: 144-164).

${ }^{12} \mathrm{Cfr}$. http://www.bapconde.com/premios-bap-conde.php
} 
representar una particular visión de la vida de los gallegos: «Maloserá», «Se chove que chova» ${ }^{13}$, etc.

Seleccionamos el primero de los spots, «Vivamos como galegos» (2007-2008) y el reciente «Se chova, que chova» (2013) a efectos de concretar y sintetizar algunos de los recursos que también se emplean en los spots que median entre estos dos anuncios y que no incluimos fundamentalmente por razones de espacio. Nos referiremos a aquellos spots seleccionados como G1 y G2, respectivamente.

Campofrío, inicialmente una empresa familiar española radicada en Burgos, es ahora una multinacional con capital extranjero, fundamentalmente mejicano y chino ${ }^{14}$. Las últimas campañas promocionales de esta empresa con más impacto ${ }^{15}$ se vertebran en torno a la vis cómica de algunos de los principales actores que en esta faceta destacan en la televisión, el cine o el circo españoles. «Cómicos» (2011), spot dirigido por Álex de la Iglesia, «El curriculum de todos» (2012) y «Hazte extranjero» (2013), dirigidos por Icíar Bollaín, de un modo análogo a lo que ha ocurrido con los anuncios de Gadis, han impactado en el público español -con incremento de compras de los productos Campofrío- y han cosechado premios para la agencia McCann Erickson, artífice de estas campañas. Las analogías entre las campañas de Gadis y de Campofrío van, sin embargo, mucho más allá de la recepción y la hábil mediación de las agencias publicitarias como veremos. Seleccionamos para mostrarlo en este estudio, «Cómicos» (2011) y el último, «Hazte extranjero» (2013), indicados en este trabajo mediante $\mathrm{C} 1$ y $\mathrm{C} 2$, respectivamente.

En todos los spots que seleccionamos es relevante, no solo como estructura profunda, sino como eje articulador tonal (pesimismo > optimismo) la secuencia elemental de funciones propuesta por Claude Brémond para analizar los relatos. Nos situamos siempre en publicidad en una perspectiva de mejoramiento donde la función inicial del relato se presenta también siempre como deficiencia, carencia o ausencia que el producto (enmascarado en estos anuncios) ha de remediar (Brémond, 1970 [1966]: 90-91 y Sánchez Corral, 1997: 39) en un proceso de mejoramiento (segunda función) ${ }^{16}$. La

\footnotetext{
13 «Se chove, que chova», ha obtenido el tercer premio de publicidad 2014. Cfr. http://www.gadisa.es/index.php? $\underline{\mathrm{id}}=6$ \&lista $=0 \&$ canal $=0 \&$ noticia $=375$

${ }^{14}$ La edición digital de El País, recogía el 23/12/2013 la paradoja de que precisamente en los momentos de emisión de la campaña publicitaria de la Navidad 2013-2014, en que la actriz Chus Lampreave se hacía eco de «esa manera tan nuestra de ser y sentir», la empresa Campofrío perdía los activos españoles: «La compañía de origen burgalés [...] hace tiempo que se convirtió en una multinacional que ahora, tras una alianza empresarial mexicano-china, estará controlada por completo por Sigma y Shuanghui. Las compañías lanzarán una oferta pública de adquisición (opa) dirigida a los actuales accionistas de Campofrío Food Group, a 6,9 euros por título, 10 céntimos más de lo ofrecido inicialmente por la cotizada y lo que supone valorar la empresa en total en 705 millones de euros. Una vez cerrado el acuerdo, tras el que la firma mexicana tendrá una participación mayor que la china, en el consejo de administración de Campofrío habrá siete miembros. Sigma nombrará a cuatro, entre ellos, el actual presidente Pedro Ballvé, hijo del fundador. Por su parte, Shuanghui nombrará a tres miembros, y uno de ellos será también vicepresidente. Cfr. http://economia.elpais.com/economia/ 2013/12/23/actualidad/1387792647 106070.html

${ }^{15}$ No solo a través de televisión donde se emiten los spots. Las redes sociales y el sitio web YouTube desempeñan un gran papel en la mercadotecnia viral de estas campañas. Véase el Twitter de Pau Gasol y la campaña «Hazte extranjero» más adelante.

${ }^{16}$ Consideramos con Sánchez Corral el carácter narrativo de los anuncios publicitarios, pero en nuestra consideración solo en la estructura profunda, puesto que el discurso publicitario narrativo no es el dominante. La descripción (discurso dominante en publicidad) del producto y de sus virtudes puede ilustrarse, eso sí, con historias que sí exigen los recursos discursivos propios de la narración. Lo veremos especialmente en G2.
} 
tercera función supone siempre el cierre exitoso de ese proceso y presenta un carácter abierto para su cumplimiento en la vida de los espectadores. El anuncio es siempre un modelo de actuación para la vida real mediante diferentes modos de identificación del espectador con los personajes del anuncio ${ }^{17}$.

La depresión inicial en el esquema de funciones de los cuatro anuncios seleccionados tiene motivaciones diferentes. En G1 la situación que ha de abandonarse para ser feliz se evoca en una fugaz escena en que el protagonista de un discurso fundamentalmente descriptivo mantiene un breve diálogo con otro personaje en una gran ciudad («-¿Qué tal? / -Aquí, a por el quinto metro del día»). Desde su llegada a Galicia (la familia acude a recibirlo), la vida estresante que ha dejado atrás da paso a un proceso de recuperación obtenido a partir de la referencia de determinados bienes relativos al paisaje, la gastronomía, la meteorología -la lluvia, asumida como un bien a pesar de la ironía o precisamente por la ironía-, el modo de ser, de inventar y de actuar de los gallegos.

La enumeración acumulativa de estos bienes, entre los cuales se incluyen tópicos atribuidos a los gallegos -reconocidos en el anuncio en clave de humor ${ }^{18}$ - se inscribe en la dirección hiperbólica y laudatoria que caracteriza al discurso publicitario (Adam y Bonhomme, 2000 [1997]). La concessio de tópicos foráneos, la correctio de propias y ajenas consideraciones («a xente non é fea, é riquiña»), la ironía y el humor («Somos os inventores do futbolín / Da pregunta total / Fran, qué [...] / Temos orballo / Carballo / Choiva / Choiva») refuerzan la dirección climática euforizante del discurso del actor principal, clímax que se pretende traspasar a los espectadores mediante la enálage del número de personas -figura de comunicación en que el «nosotros» sustituye al «yo» y al «tú» (cfr. Perelman, 1989: 284).

El traspaso metonímico de los bienes gallegos elogiados por el actor del anuncio a los espectadores mediante la mencionada enálage crea vínculos de unión anímica, de identidad cultural presente, de autoestima y de potenciación de los bienes en un sentido teleológico. Los reiterados «somos», «temos» fundamentan la optación del eslogan «Vivamos como galegos», en que se funden la identidad presente de bienes compartidos («galegos»= somos y tenemos todo esto) con una identidad futura vista en clave emocional y hedónica («Vivamos»= conciencia de lo que somos y tenemos [«Deámonos conta do ben que vivimos»] y disfrute de todo ello [«gocemos da nosa forma de vida»]). La falacia común a todos los anuncios consiste en la ocultación de cualquier obstáculo que pudiera presentarse en el proceso de mejoramiento (se seleccionan imágenes idílicas, situaciones cómicas, reuniones y encuentros alegres), y, en este anuncio, además en la ocultación de los productos vendidos por Gadis (solo presentados sutilmente): productos de la tierra ocultos en el nombre de los recolectores (percebeiros, greleiras ${ }^{19}$ ), gastronomía (la tortilla hecha por la madre y la degustación de

\footnotetext{
${ }^{17}$ Sobre los modelos de identificación del lector con los personajes de las obras literarias, su explicación histórica y su aplicabilidad a la publicidad, cfr. Jauss (1986 [1977]: 259-291) y Rodríguez Fontela (2004: 5).

${ }^{18} \mathrm{Cfr}$. «E se alguén te pon en apuros, respóndelle con outra pregunta». Entendemos el término 'humor' aquí en una doble dirección. Por un lado, se pretende distender ( $c f r$. León, 2001: 145) y divertir al espectador y, por otro, actuar con la autocrítica característica del propio humor de los gallegos.

${ }^{19}$ La Real Academia Galega ha incluido en su diccionario la acepción de 'greleiro' que se emplea en este spot. Cfr. http://gadis372.wordpress.com/2008/02/02/greleiroa-acepciones-en-la-rag/. En esta dirección, entre la promoción publicitaria de bienes culturales, habría que destacar también la difusión y potenciación de determinadas expresiones
} 
la muchacha probando comida en la cocina) y la nevera abierta llena de alimentos. El nombre de la marca sobreimpresa en la última escena reivindica el patrocinio del spot precisamente en el punto climático de imagen y música más elevado.

Un argumento sostiene este proceso de mejoramiento (autoafirmación en una identidad colectiva e invitación al goce de lo que se es y se posee) en una dirección optimista, tan en la línea de los manuales de autoayuda, de las terapias de autoestima y de otras manifestaciones del carpe diem posmoderno. Se trata del argumento de superación que, en palabras de Perelman, «insiste[n] en la posibilidad de ir siempre más lejos en un sentido determinado, sin que se entrevea un límite en esta dirección, y esto con un crecimiento continuo de valor» (Perelman, 443). El optimismo, la orientación hacia el futuro, la vinculación con la libertad -que veremos-, el deseo de cambiar sin reparar en dificultades son las marcas más notables de este argumento.

El argumento de superación potencia desde el ámbito de la nueva retórica, como vemos, la secuencia elemental de funciones del narratólogo Brémond en la perspectiva de mejoramiento comentada, y su presencia se advierte en todo las partes artis: desde la intellectio -briefing, en publicidad-, pasando por la inventio -acumulación de imágenes y de texto lingüístico sustentados en el lugar común de cualidad (se señala lo único: los inventores, la calidad de los productos naturales y gastronómicos), en el lugar común de orden (la tradición que justifica valores actuales: ritmo lento de vida, valores familiares, etc.), en el lugar común de esencia (la perfección de determinados bienes: las mejores playas del mundo, el mejor fútbol)-; por la dispositio - patente en la acumulación de imágenes idílicas, en la música (Oda a la Alegría de la Novena Sinfonía de Beethoven) y, especialmente, en la evocación de un pasaje de Braveheart (1995) que remite al valor de la libertad de vuelos nacionalistas cuya defensa asume William Wallace en el film de Mel Gibson ${ }^{20}$; hasta la llegar a la actio.

La actio $^{21}$ publicitaria desempeña un papel fundamental en la expresión del argumento de superación hasta el punto de que podemos hablar de determinados tópicos gestuales y proxémicos en la expresión de este argumento. En G1 la actio de superación sirve además para reforzar los lazos comunitarios de identidad en torno a los valores de los que hemos hablado. Nos referimos, en primer lugar, al tono ascensional modulado de la voz del actor principal (graves-agudos-graves-agudos) con quiebros humorísticos para significar o reforzar el humor de determinadas escenas. En segundo lugar, a las relaciones cordiales amistosas o familiares - expresadas en sonrisas y proximidad física (caricias, abrazos, pases de baile)-, a los gestos de firmeza del actor principal en la exhortación a los

propias del idioma que sufren en la labor creativa del anuncio transformaciones innovadoras. $C f r$. a este respecto, el término «Maloserá» de spots posteriores que hace referencia al modismo gallego: «malo será».

${ }^{20}$ El pasaje evocado por el spot de Gadis es aquel del film de Gibson en que Wallace habla montado a caballo exhortando a los escoceses a la lucha. Dicho pasaje fue empleado con anterioridad en el discurso publicitario de la cerveza Schneider, por lo que se acusó de plagio a la empresa Bap \& Conde. No entraremos ahora en las vicisitudes concretas de esta relación intertextual y en la cuestión de plagios y relaciones intertextuales e interartísticas de la publicidad, cuestiones que merecen un estudio más profundo. Solo destacamos ahora que este préstamo fílmico fue reiteradamente usado en otros anuncios de Gadis y se convirtió en un referente identificador de la línea de spots de aquella empresa gallega. Cfr. https://www.youtube.com/watch?v=7HhAaLBW9do, y https://www.youtube.com/watch?v=Em67D14UY_o (5/11/14)

${ }^{21}$ Recordemos que la actio retórica atañe fundamentalmente a los componentes paralingüísticos (tono, entonación), kinésicos (mímica y gestos) y proxémicos (distancia, actitud y movimiento de los personajes) de la representación del discurso. 
espectadores que aparecen en el spot y que son imagen de los espectadores del anuncio, y especialmente, a los brazos en alto de un público muy amplio que, si nos fijamos, aparecen en los picos más altos de la línea climática del anuncio.

El humor es otro aspecto que contribuye a reforzar el argumento de superación. Particularmente en este anuncio, el humor tiene dos funciones: por un lado contribuir al efecto hilarante -objetivo casi siempre buscado en publicidad en lo que tiene de función catártica y expresión de una sociedad libre y tolerante ( $c f r$. León, 2001: 145)- y, por otro lado, tematizar el humor gallego -la retranca- como valor propio. Con respecto a esto, el anuncio de Gadis pone de relieve, bajo la sonrisa de los personajes y a través de los diálogos -obsérvese la reiteración de «Bueno» en las respuestas dadas por el hombre a las preguntas de la mujer en la escena cuarta del anuncio ${ }^{22}$, una filosofía de vida en que domina la adaptación ocurrente de valores o exigencias foráneas al contexto gallego - $c f r$. la traducción al inglés de «pulpo á feira» en un menú de bar («pulpo a la gallega», en sobreimpresión > «octopus to the party» en la pizarra anunciadora), o el «hand parking» convertido en gesto de manos acompañado de «aí, aí, aí»- y la aceptación de la realidad con optimismo ${ }^{23}$-«Temos orballo», «carballo», «choiva, choiva... e choiva», expresiones recurrentes manifestadas en tono irónico que implican esta aceptación.

Optimismo y filosofía de vida se acentúan en «Se chove, que chova», el último de los spots de Gadis que ha obtenido recientemente un nuevo galardón para BAP \& Conde. La función inicial representa el contexto de la crisis como en anteriores anuncios, que no estudiamos aquí, para expresar las nuevas dificultades que los gallegos han de afrontar. El diálogo «filosófico» inicial, más bien serie de elucubraciones de carácter imaginativo, tiene lugar precisamente en un espacio poco dado a profundidades: una peluquería de señoras -paradoja de efecto humorístico-. Este recurso desautomatizador, poético en su ironía, sirve para introducir las nuevas dificultades que los gallegos han de superar - una de las señoras se refiere a las malas noticias de la prensa-con la ayuda de Gadis.

La función que inicia el proceso de superación se presenta cuando la más activa de las señoras dialogantes se convierte en narradora de una historia que parece salida de la materia de Bretaña en versión light: sus nietos se internan en un bosque para preguntar «ao home más sabio de Galicia» «se habería algún sitio en Galicia que non se nubrase nunca»-en referencia a la climatología, pero, metafóricamente, a la situación de crisis-. El sabio resulta ser sabia ${ }^{24}$ y la respuesta, telúrica: «O único que non se nubra nunca en Galicia é a nosa alegría... Porque a nosa alegría ven da nosa forza... E a nosa forza ven da terra». A partir de aquí, y desde este condicionamiento de la tierra y el paisaje, se hace una descripción del carácter gallego: «Os carballos e os acantilados fannos recios... os ríos, un pouco enrevesados... a choiva, creativos... e os atardeceres, sensibles e morriñentos».

\footnotetext{
22 Seguimos la secuencia de escenas señaladas por Screti (2011: 225-228), para analizar este anuncio de Gadis.

${ }^{23}$ El optimismo latente (argumento de superación implícito) en la aceptación de la realidad, explotado aquí humorísticamente, aparecerá también en posteriores spots de Gadis, especialmente manifiesto en los eslóganes específicos: «Maloserá», «Se chove, que chova».

${ }^{24}$ Este nuevo recurso de desautomatización es un doble guiño al contexto donde se narra la historia -la peluquería- y al discurso feminista contemporáneo: parodia y humor posmodernos.
} 
Este telurismo, muy presente en los anuncios de promoción turística de Galicia, con análogas imágenes incluso ${ }^{25}$, nos devuelve al terreno de las emociones, del hedonismo, y de la estetización de imágenes que, como nos recuerda Maffesoli, etimológicamente significa «anteponer las pasiones comunes» (Maffesoli, 2009 [2008]: 85). Y pasiones comunes encontramos en este anuncio: en la tertulia de la peluquería, en el legado de la tierra al carácter de los gallegos, en la enumeración ilustrativa de dificultades superadas una y otra vez en todo tiempo, en la explosión de júbilo casi final para invocar el grito dionisíaco de la tribu -«Vivamos como galegos»- en contextos diferentes: la gente de la peluquería, la del estudio radiofónico que a través de las ondas difunde la alegría compartida a otros ámbitos urbanos - la carretera, los bares-. Todos, con los brazos en alto, como ya hemos visto en el anuncio anterior, expresan en diversos planos y diversos ángulos -picado, ligero picado, normales y ligeros contrapicados- la victoria de las pruebas superadas con trabajo pero con fiestas, con bailes, con playa y baño en agua fría que siempre está muy buena, con comidas, meriendas y cenas -a las que sirve Gadis sin ser visto, claro-, con visitas sanadoras llenas de regalos y, sobre todo, con ánimo firme y despreocupado - «Como di o meu Paco: Se non me preocupa viaxar no espacio, nunha bola enorme a miles de kms. por segundo entre meteoritos e lixo espacial ¿voume preocupar polo demais?» (locución acompañada de la falaz imagen del cosmos, sin basura y sin meteoritos)-.

La apoteosis de «Vivamos como galegos», que parecía final dado su potencial climático, deja paso a la apoteosis que explica el nuevo eslogan. Los brazos en alto, que evidencian la actio característica del argumento de superación en estos anuncios de Gadis, en otros anuncios publicitarios y en otros medios como el cine, aparecen de nuevo, tras un silencio fílmico, al final del spot. La lluvia sorprende a las señoras cuando salen de la peluquería dispuesta a llevarse sus peinados y el dinero invertido en ellos. La reacción de las mujeres, tras tanta lección de superación, no se hace esperar: elevan sus brazos y contagian su alegría con fondo de gaita -en imagen y en música- a las peluqueras, a los transeúntes y hasta al caballo de William Wallace. «Se chove, que chova» es la máxima de una forma de vida y el antídoto contra todo tipo de adversidad. «A que está caendo», que dice una de las mujeres, es la lluvia y también la crisis, pero las mujeres siguen desafiándola con los brazos en alto y con la alegría compartida, el secreto que reveló la mujer sabia a los nietos de la abuela más parlanchina de la peluquería.

¿Dónde está Gadis en este anuncio? Análogamente al spot anterior aparece en la comida de las fiestas -se recicla incluso una imagen de aquel primer anuncio para evocar una comida familiar en un espacio rural- en otros contextos festivos, en el puesto de venta de productos ecológicos al aire libre, y, explícitamente G2, en el perro labrador que lleva en su boca una bolsa con el logotipo de la marca Gadis - product placement, en lenguaje publicitario- y en la rúbrica sobreimpresa del mismo logotipo al final del spot, como en anuncios anteriores.

Hay un aire de familia hecha de tópicos y de estrategias procedentes de la misma agencia publicitaria y hay una labor intertextual que establece lazos aún más profundos entre los spots de

${ }^{25} C f r$. el spot «Galicia, destino atlántico» en https://www.youtube.com/watch?v=n7RITqVEPyE $(5 / 11 / 14)$ 
Gadis. El caballo de Wallace ${ }^{26}$, por ejemplo, reaparece en «Se chove, que chova» al final del anuncio, pero también en la versión infantil de los ponis y otros caballos de pequeña alzada que acompañan a los niños de la historia que cuenta la abuela en la peluquería; la gaita de «Vivamos como galegos en Nueva York» (2008-2009) o de «Supergalegos» (2010) reaparece en la apoteosis final de «Se chove, que chova», etc. Los efectos de esta labor intertextual no están solo destinados a ofrecer un aire de familia que refuerce la marca, sino también a fortalecer los símbolos de identidad y, simultáneamente, a desmitificarlos, pues la parodia que supone la reaparición implica la pérdida del aura mítica. La civilización del espectáculo se impone con su prioritario valor de entretenimiento que, según observa Vargas Llosa (2012: 33-34), contribuye a banalizar la cultura.

En «Comicos», spot de McCann Erikson para Campofrío, la primera función -el desánimo que produce la crisis- persiste, con el paréntesis de la comida, hasta la aparición de Miguel Gila. Cómicos españoles como Santiago Segura, que actúa de narrador con voz en off, Chiquito de la Calzada, Fofito, las hermanas Hurtado, los Morancos, Mago Mora, Florentino Fernández, Andrés Pajares, Forges, Martes y Trece, Fernando Esteso, Anabel Alonso, Bigote Arrocet, Tony Antonio, Pepe Carabias, Juan Luis Cano se reúnen para homenajear al que ellos llaman su «maestro», Miguel Gila. El hecho de que los actores sean conocidos y de que el humorista homenajeado también lo haya sido de la población de más edad contribuye a restar carácter ficcional al spot que puede verse como lo que también es además de un anuncio de los productos de Campofrío: un homenaje a Miguel Gila.

Hay sin embargo elementos que unen este anuncio con los de Gadis que hemos comentado. En primer lugar, el contexto de la primera función que abre la secuencia de mejoramiento y fundamenta el argumento de superación: el desánimo que produce la crisis económica española de estos últimos años 2008-2014. Es significativo a este respecto que la ilustración de esta crisis provenga en «Se chove, que chova» y en «Cómicos» de la prensa escrita; en G2, en forma de comentario de una de las clientas de la peluquería sobre lo que lee en un diario - «Digoche que xa non se pode ler nada. Todo son malas noticias. E que che amargan a vida»-, y, en C1 de una alusión de Santiago Segura cuya referencia está en el titular del periódico Economía: «La crisis continúa»-otro dato para la pérdida de la naturaleza ficcional del anuncio-; «Hay días en que uno no se levanta con ganas de sonreír y mucho menos de hacer sonreír a los demás. Esos días donde la realidad parece tener un solo punto de vista: el negativo».

En segundo lugar, el argumento de superación se da en estos dos anuncios por la vía emocional. En G2, a partir de situaciones que exponen el modo de vivir y sentir de los gallegos -la superación de pruebas con aceptación, optimismo y disfrute-; en C1, a partir de la comida en que se toman bocadillos con productos de Campofrío - product emplacement- y, fundamentalmente, a partir de la respuesta que Miguel Gila da a la pregunta formulada por Josema Yuste, de Martes y Trece: «Maestro, ¿se puede ver cada día el lado bueno de todo con la que está cayendo?» (cfr. «a que está caendo» al final de $\mathrm{G} 2)$.

${ }^{26}$ Símbolo de libertad, pero también de fuerza y de superación. 
En tercer lugar, el móvil -referencia intermedial ${ }^{27}$ - cumple en G2 y C1 un papel determinante en la introducción de nuevos espacios y nuevas historias. En G2 es el medio por el que llega la conversación de la peluquería a una cadena de radio que la emite en directo y llega, como si de una sesión de coaching se tratara, a los que están conectados a la cadena. En C1, el móvil permite acceder a otro mundo, el de Gila, guardado en la memoria y en los archivos de televisión.

Finalmente, vincula a G1, G2 y C1 el humor. Con recursos de ironía en los tres casos, pero con ironía de carácter diferente. En los gallegos, la ironía se tematiza como parte del carácter gallego y en $\mathrm{C} 1$ se presenta como recurso de gremio. El potencial de humor de «Cómicos» proviene de su propia imagen, al ser conocidos de los espectadores, de sus tics y símbolos característicos $-c f r$. la flor roja de Fofito-, de su actio - cfr. de nuevo Fofito, relamiendo el bocadillo con los embutidos de Campofrío, y la indumentaria típica de cada uno de ellos- y de sus chistes de siempre que repiten de memoria una y otra vez y ahora, una vez más, para animarse («fingimos reírnos como si fuera nuestra primera vez»): «estás más delgado», «te está creciendo el pelo»-frase esta última dirigida a Santiago Segura.

Hay, sin embargo, diferencias fundamentales. El humor en $\mathrm{C} 1$ es menos festivo y menos optimista. Esto se debe, en primer lugar, a la estructura quebrada de la secuencia de funciones que rigen el argumento de superación. Esto es, hay un primer proceso de mejoramiento expresado por el encuentro y la comida de bocadillos y los abrazos y chistes prodigados en torno a la mesa. Para todos los cómicos, sin embargo, esta fraternidad es una ficción llena de voluntad pero poco persuasiva para reír y hacer reír. Falta lo fundamental: el ánimo del maestro. La recuperación de su ánimo vendrá de la respuesta a la pregunta que dirigen solemnemente al maestro, respuesta que llega a todos y cada uno de los móviles. El argumento de autoridad que supone la aparición de $\mathrm{Gila}^{28}$ con su conocido monólogo es lo que realmente mueve anímicamente a los cómicos al final del anuncio.

En segundo lugar, el humor es menos festivo porque el argumento de superación no se expresa como es habitual en los otros anuncios comentados y en otros muchos. No aparecen brazos en alto, solo abrazos, repartidos en el encuentro que precede, acompaña y sigue a la comida y, especialmente, cuando Gila responde con su conocido monólogo. El ánimo positivo no deriva, pues, tanto de los productos de Campofrío cuanto del ser humano que representa una autoridad incontestable en el dominio de la adversidad mediante el oficio de cómico. Reír y hacer reír fue el gran remedio de Gila para una vida azarosa llena de contratiempos. El ánimo compartido en este anuncio es, pues, gremial y Gila justifica la acción de los cómicos en tiempos de crisis: los hace reír con ganas al final -otra

\footnotetext{
${ }^{27}$ Asumimos en este concepto una relación entre los medios más estrecha que la que vimos más arriba en el concepto de transmedialidad: una correlación, interferencia o diálogo entre los medios, sea, como en este caso, porque un medio se presenta dentro de otro formando parte del mensaje y de su estructura, sea porque la relación se dé en las actividades de mediación y transformación de los medios - por ejemplo, la publicidad en el cine, en la prensa o internet-.

${ }^{28}$ Miguel Gila (1919-2001) es un conocido humorista de la posguerra y de los años de la transición que publicó viñetas en varias revistas de humor -La Exedra, La Codorniz, Hermano Lobo- y se dio a conocer del gran público a través de la televisión con sus monólogos-diálogos con «el enemigo», vestido de soldado, tal como se muestra en el spot. El fundamento de su autoridad para los cómicos españoles actuales reside no solo en su buen hacer, en su peculiar estilo humorístico próximo a lo absurdo y no exento de ternura, sino, sobre todo, en su autobiografía real en la que no faltó el hambre, el exilio, la cárcel y hasta un fusilamiento del que Gila sobrevivió milagrosamente. Su vida realmente fue un ejemplo de superación de las adversidades por la vía del humor.
} 
manifestación de la actio de superación- y esta risa y los últimos abrazos expresan el ánimo, ya firme, que han de compartir con su público mediante su propio hacer reír.

«Que nadie nos quite nuestra manera de disfrutar la vida», la frase que acompaña al logotipo de Campofrío en la clausura del spot $\mathrm{C}$, es un indicio del sentido comunitario más amplio que veremos en anuncios posteriores de aquella marca. El humor de los cómicos es la sinécdoque del humor español que aparecerá reivindicado en un sentido nacionalista -análogamente a lo que hemos visto en los de Gadis- en «El curriculum de todos» y en «Hazte extranjero» (C2).

$\mathrm{C} 2$, siguiendo la senda trazada por «El curriculum de todos» $\mathrm{y}$ «Cómicos» emplea como recurso de identificación con el espectador, a diferencia de lo que hemos visto en Gadis, la presencia de cómicos, actores profesionales, periodistas, etc., conocidos del gran público ${ }^{29}$. En C2, una actriz cómica, Chus Lampreave, que ya había actuado en «El curriculum de todos» con gran protagonismo, representa con su voz en off y voz en in el discurso lingüístico que vertebra todo el anuncio. Este discurso está tejido de monólogos y breves diálogos con los personajes que Chus Lampreave va encontrando al paso en un espacio globalizado por la ficción, pero con la arquitectura y el trazado de Alcalá de Henares: una especie de feria con stands donde diferentes estados expiden diplomas que acreditan la nueva nacionalidad de los españoles.

La ficción que crea la campaña «Hazte extranjero» conecta bien, por un lado, con la situación real del país donde muchos tienen los deseos de huir que manifiestan los personajes del spot, y, por otro lado, revela el sentido del humor reivindicado como seña de identidad de todos los españoles. «Hazte extranjero» no deja de ser, a este respecto, un revulsivo hiperbólico para rescatar la conciencia de los bienes culturales que crean un carácter y una identidad nacional.

La situación carencial de la primera función es, como en $\mathrm{G} 2$ y C1, la crisis, pero en este caso, entendida en un sentido amplio, lo que refuerza el complejo de inferioridad de los españoles y su deseo de huir. «Todos los estudios lo dicen - dice Chus Lampreave-: somos los últimos del ranking». «¿De cuál de ellos?»-pregunta Juan Ramón Lucas-. «¡Pues de casi todos!»-responde Lampreave, al lado de un cartel que, en manos de un joven, proclama en grandes letras «Nuestro país a la cola en educación». Ella misma en su vuelo imaginativo quiere hacerse jamaicana, mientras Verónica Forqué se apunta a una nacionalidad mixta franco-rusa, inspirada en el vuelo real de Gérard Depardieu, «el actor ese tan gordo».

Una vez emprendida la huida imaginativa, Chus Lampreave, pondera las ventajas y desventajas de hacerse extranjera. El peso de lo que tendría que abandonar se impone. «¿Qué hacemos con lo de...?»-dice Lampreave, y empieza a enumerar: «abrazarnos y tocarnos todo el rato», «hablar a gritos como si estuviéramos sordos», «el sentido del humor», «invitar aunque no tengas un duro», «cocinar pa tres y que coman quince»-interviene Rosario Flores-, «luchar aunque no tengas fuerzas»-dice El Langui-. «Que hacemos con todo eso»-resume Chus Lampreave-. ¿Y qué es eso? «Algunos le llaman

\footnotetext{
${ }^{29}$ Aparte de Chus Lampreave, se reconocen los humoristas Chiquito de la Calzada, Enrique San Francisco, Goyo Jiménez, Leo Harlem, las hermanas Hurtado; periodistas como Juan Ramón Lucas, Javier Sardá; actores como Gabino Diego; cantantes como Rosario Flores, e incluso algún cocinero como Martín Berasategui.
} 
carácter o cómo somos [...]. Esa manera nuestra de ser y sentir a la que no puedes renunciar porque va contigo siempre», enfatiza Lampreave. La actriz protagonista ha trazado con la ayuda de los compañeros que actúan en el spot un cuadro básico de los bienes culturales españoles, esta vez concebidos como carácter o modo de ser, en todo caso con valor de identidad nacional ${ }^{30}$. «Seas de donde seas y estés donde estés», dice Pau Gasol asomado a la pantalla del ordenador ${ }^{31}$ al final del anuncio, evocando de este modo la realidad virtual de las redes sociales y en concreto el tweet en el que el deportista comunicaba la propuesta que se le había hecho para obtener la nacionalidad americana, y evocando también la pantalla del televisor que aparece al comienzo del anuncio y en el que se recoge un anuncio alusivo a la campaña - «¿Cansado de ser de aquí? ¿Harto de tu país de pandereta? Hazte extranjero»-. «Uno puede irse, pero no hacerse», subraya al final Chus Lampreave deteniendo la mano que firmará la acreditación de su nueva nacionalidad sueca.

Al final, el desánimo se ha superado con el recuento y reconocimiento de todos esos bienes, con la evidentia fílmica de las imágenes en las que puede verse, como también ve Chus Lampreave, la satisfacción de sus compañeros paisanos con esos modos de ser y de actuar y, sobre todo, con la comida en la que todos participan con productos de Campofrío, algunos salidos como conejos de la chistera -Chiquito de la Calzada-. El grupo se une en torno a esta forma de vida y goce. La fiesta de las últimas escenas, con los farolillos de colores, los brindis, las risas y las animadas conversaciones, lleva al clímax de la actio el argumento de superación. Ya no se recuerdan los motivos que generaron la campaña, los deseos de huir. Sólo queda la fiesta y la optación final: «Que nada ni nadie nos quite nuestra manera de disfrutar de la vida». La tradición, el lugar común de orden, se impone. El hedonismo también.

Como podemos ver en los cuatro anuncios que comentamos, partimos siempre de una situación negativa: el estrés, el desánimo producido por la crisis y los complejos de inferioridad colectivos que se superan con una relación de bienes culturales optimizados con el recurso del humor y la ironía. En los cuatro es fundamental la presencia de la comida compartida en fiestas familiares, gremiales o populares donde se representan de un modo directo los productos de Campofrío y, de un modo implícito e indirecto, los de Gadis.

Desánimo inicial $\longrightarrow$ Relación de bienes culturales Euforia final, autoafirmación <crisis, complejos>

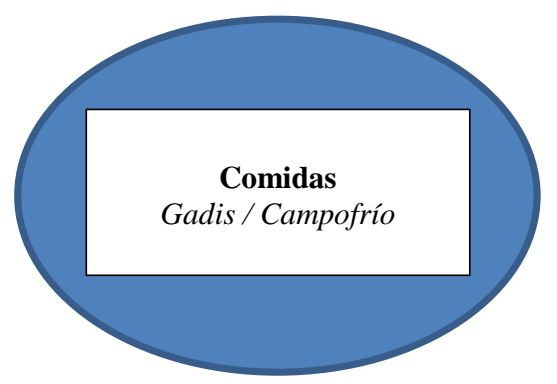

\footnotetext{
${ }^{30}$ En «El curriculum de todos», los bienes culturales estaban basados en la excelencia -lugar común de esencia- de los españoles en determinados ámbitos, literatura, deportes, etc.

${ }^{31}$ Los «otros medios» desempeñan, como en anuncios anteriores, un papel importante.
} 
Los cuatro anuncios son exponente de un acto directivo ${ }^{32}$-el consejo de compra está aunque esté velado- y de un acto de habla indirecto en cuanto el acto directivo queda implícito. En la publicidad de Gadis y Campofrío no se nos invita directamente a comprar los productos; se nos invita a comprarlos valorando el contacto metonímico de los productos vendidos por esas marcas con comidas familiares, encuentros festivos presididos por los valores de comunión familiar, grupal y nacional que en esas mesas se encuentran. Se nos invita a comprar los valores que los productos comportan. Y se nos invita a comprarlos además porque, por esta vía indirecta, se resuelven los problemas iniciales de los actores-personajes, imagen de los espectadores.

La publicidad de Gadis y Campofrío va mucho más allá en la profundización del acto de habla indirecto. El consejo implícito de compra de los productos no solo se canaliza por los valores comunales a ellos asociados, sino también por el valor estético y cultural que representa la propia publicidad. Los componentes estéticos comentados, la intertextualidad de los spots de cada marca y el fenómeno cultural de masas que comporta la relación intermedial de las campañas nos invitan a comprar los productos de aquellas marcas también porque valoramos su publicidad ${ }^{33}$.

En estos momentos en que con la globalización domina la desterritorialización de los bienes y valores culturales, la publicidad se erige, al menos en los anuncios que comentamos, en cauce de reterritorialización ${ }^{34}$ para valores culturales gallegos y españoles. En los anuncios de Gadis se seleccionan y se hacen visibles los valores de la tierra - la tierra misma y su poder telúrico, los árboles, el mar, los ríos, los paisajes rurales, la madre ctónica (representada simbólicamente en la madre que hace la tortilla y en las abuelas de la peluquería), los productos naturales del campo y del mar-; se potencia en imágenes y discurso lingüístico la retranca, manifestación autóctona de la ironía -sonrisa de los actores, aceptación del destino, conciliación en el diálogo, lleno de concesiones pero también de correcciones-; y los valores de libertad con ciertos tintes nacionalistas, asociados como están al caballo del héroe escocés William Wallace.

En los spots de Campofrío, sobresale, sobre todo, el sentido del humor español, muchas veces en la vía del absurdo y la ternura que representa el humor de Gila. Se destaca la cordialidad hecha de caricias y abrazos; el espíritu festivo desmedido en volumen de voz y en nocturnidad; la hospitalidad y el compartir en la pobreza; el espíritu de lucha; el ánimo siempre dispuesto para una comida, una reunión y una fiesta.

No profundizaremos aquí en el carácter nacionalista del mensaje de estos anuncios, porque el examen del concepto de nación requiere mayor espacio. No podemos dejar de señalar, con todo, que tanto el carácter nacionalista como los valores y el perfil de una identidad cultural propia que apreciamos en estos spots se trazan con esa línea de los mitos y manifestaciones de la posmodernidad

\footnotetext{
32 Seguimos en estos conceptos la clasificación de actos ilocutivos de Recanati (1981) recogida por Nicole EveraertDesmedt en su aplicación a la publicidad (2005: 2-5). Acto directivo es aquel en el que la transformación de la realidad está a cargo del interlocutor. En el caso de la publicidad, la compra del producto por parte del espectador.

${ }^{33}$ Cfr. el concepto de publicidad moderna en Everaert-Desmedt (2005: 8-16).

${ }^{34}$ Sobre los conceptos de desterritorialización y reterritorialización, cfr. García Canclini (2001 [1999]: 281-297).
} 
que se compadecen, por otra parte, con los efectos persuasivos, propiamente emocionales, de las estrategias retóricas de la publicidad. La imposición de las imágenes y su acumulación vertiginosa y fragmentada, el hedonismo y el cultivo de emociones y afectos, el grito casi tribal que se percibe en algunas escenas de los spots de Gadis, el propio sentido del humor visto como valor cultural pero también utilizado como recurso retórico en la ironía y la parodia, juntamente con la tematización de la propia publicidad en los numerosos préstamos intertextuales y en las relaciones intermediales, todo ello nos habla de una cultura que expresa sus propios activos de un modo fragmentado, simplificado, banalizado, sin articulación lógica y sin pensamiento crítico profundo. De todos modos, estas manifestaciones significantes publicitarias de la cultura que son los anuncios impactan masivamente -como el fútbol y los espectáculos musicales igualmente masivos- y condicionan y reformulan la cultura para futuras generaciones como textos en que la cultura propia se lee de un modo dominante. Crean identidad cultural porque un gran número de espectadores se identifican con los valores en ellos expresados.

\section{Bibliografía}

BAUDRILlARD, Jean (2000 [1979]): De la seducción. Madrid, Cátedra.

BeristáIn, Helena (1985): Diccionario de Retórica y Poética. México, Porrúa.

BoURDIEU, Pierre (1997 [1996]): Sobre la televisión. Barcelona, Anagrama.

BRÉMOND, Claude (1970 [1966]): «La lógica de los posibles narrativos», en Roland Barthes et al., Análisis estructural del relato. Buenos Aires, Tiempo Contemporáneo.

EVERAERT-DESMEDT, Nicole (2005): «La evolución del discurso publicitario», conferencia del Segundo Congreso mundial de Semiótica y Comunicación: «La dimensión de los Mass-Media», 19-22 de octubre de 2005, Monterrey, México. Accesible en http://nicole-everaert.host56.com/ web_nicole/PDF/esp/Evolucion\%20de\%20la\%20publicidad.pdf

GARCÍA CANCLINI, Néstor (2001 [1999]): Culturas híbridas. Estrategias para entrar y salir de la modernidad. Barcelona, Paidós.

GEERTZ, Clifford (2000 [1973]): La interpretación de las culturas. Barcelona, Gedisa.

JAUSS, Hans Robert (1986 [1977]): Experiencia estética y hermenéutica literaria. Ensayos en el campo de la experiencia estética. Madrid, Taurus.

Kattenbelt, Chiel (2008): «Intermediality in Theatre and Performance: Definitions, Perceptions and Medial Relationships», Cultura, Lenguaje y Representación, VI, pp. 19-29.

LEÓN SÁEZ DE YBARRA, José Luis (2001): Mitoanálisis de la publicidad, Barcelona, Ariel.

— (2007): «Prólogo», en Belén López Vázquez, Publicidad emocional. Estrategias creativas. Madrid, ESIC.

MAFFESOLI, Michel (2009 [2008]): Iconologías. Nuestras ideologías posmodernas. Barcelona, Península. 
MCLuHAN, Marshall (1996 [1964]): Comprender los medios de comunicación. Las extensiones del ser humano. Barcelona, Paidós.

Perelman, Chaïm., y Olbrechts-Tyteca, L. (1989 [1958]) : Traité de l'argumentation (La nouvelle rhétorique). Bruselas, Université de Bruxelles, $5^{\mathrm{a}}$ ed. Trad. de J. Sevilla Muñoz, Tratado de la argumentación. La nueva retórica, Madrid, Gredos, 1989.

RODRíGUEZ Fontela, M. ${ }^{a}$ Ángeles (2004): «Publicidad y discurso autobiográfico», en Celia Fernández y M. ${ }^{a}$ Ángeles Hermosilla, Autobiografía en España. Un balance. Madrid, Visor, pp. 589-98. Accesible también en http://docs.lib.purdue.edu/cgi/viewcontent.cgi?article=1911\& context=clcweb

SÁNCHEZ CoRRAL, Luis (1997): Semiótica de la publicidad. Narración y discurso. Madrid, Síntesis.

SCRETI, Francesco (2011). «La banalización de la nación: el anuncio Vivamos como galegos de supermercados GADIS», Revista Comunicación, 1, 9, pp. 222-237. Accesible en http://www. revistacomunicacion.org/pdf/n9/miscelanea/m05.La_banalizacion_de_la_nacion.pdf (5/11/14)

Vargas Llosa, Mario (2012): La civilización del espectáculo. Madrid, Alfaguara.

Williams, Raymond (1976 [1958]): Culture and Society. 1780-1950. Ontario, Penguin Books. (1982 [1981]): Cultura. Sociología de la comunicación y del arte. Barcelona, Paidós.

\section{Otras fuentes electrónicas}

http://www.bapconde.com/premios-bap-conde.php (5/11/14)

http://www.gadisa.es/index.php?id=6\&lista=0\&canal=0\&noticia=375 $(5 / 11 / 14)$

http://economia.elpais.com/economia/2013/12/23/actualidad/1387792647_106070.html (5/11/14)

http://gadis372.wordpress.com/2008/02/02/greleiroa-acepciones-en-la-rag/ (5/11/14)

https://www.youtube.com/watch?v=n7RITqVEPyE (5/11/14)

https://www.youtube.com/watch?v=7HhAaLBW9do (5/11/14)

https://www.youtube.com/watch?v=Em67D14UY_o (5/11/14)

\section{Spots de GADIS y CAMPOFRÍO}

«Vivamos como galegos», 2007/2008 (G1)

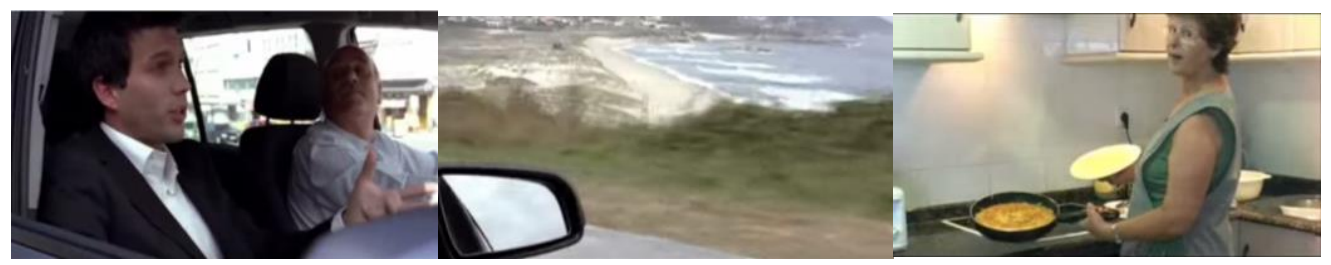


144 | Tropelías. Revista de Teoría de la Literatura y Literatura Comparada, 22 (2014) M. ${ }^{a}$ Ángeles Rodriguez Fontela
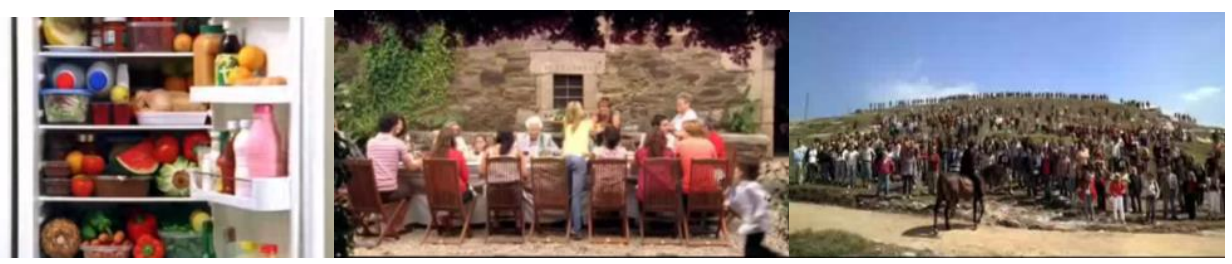

https://www.youtube.com/watch?v=jaY8QCoPyqY (5/11/14)

https://www.youtube.com/watch?v=UzIooUMObSg (versión subtitulada)
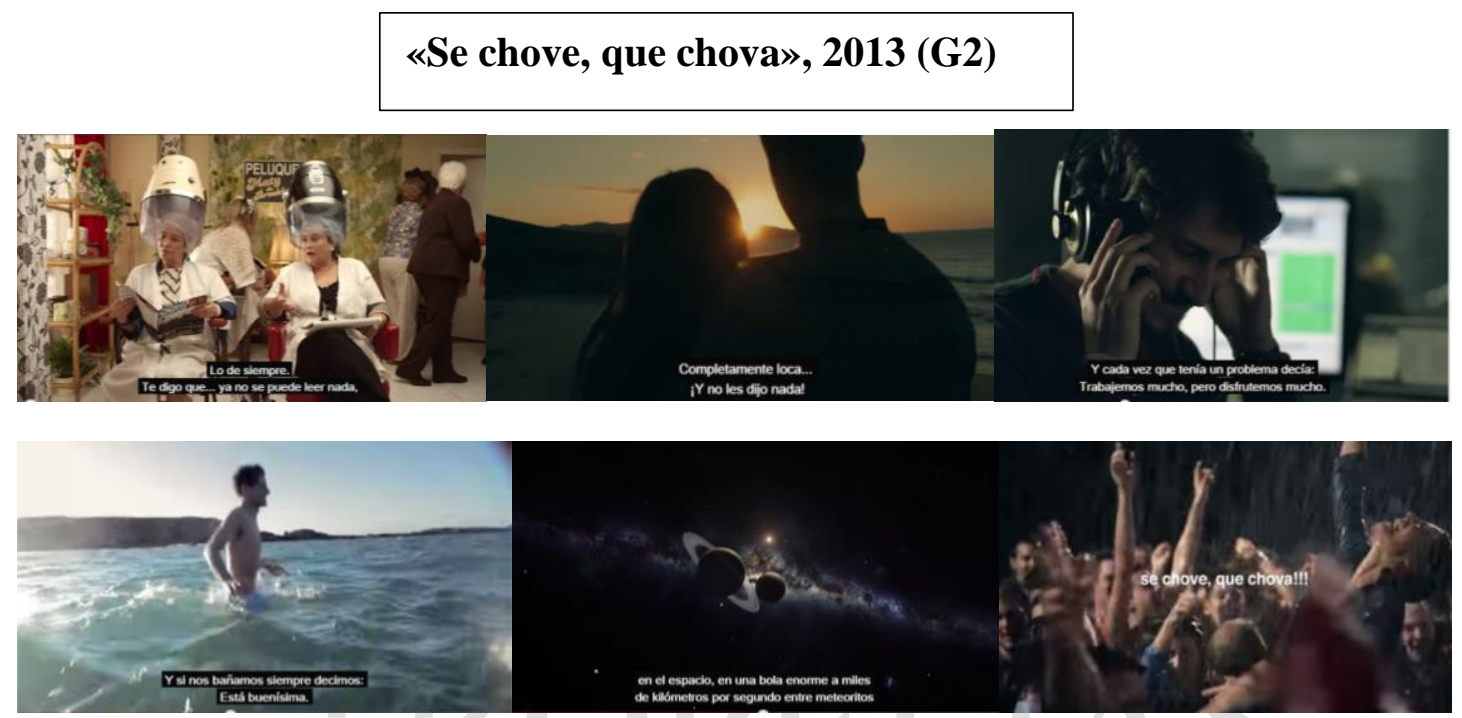

$<$ https://www.youtube.com/watch?v= jKK58hkG5s $(5 / 11 / 14)$

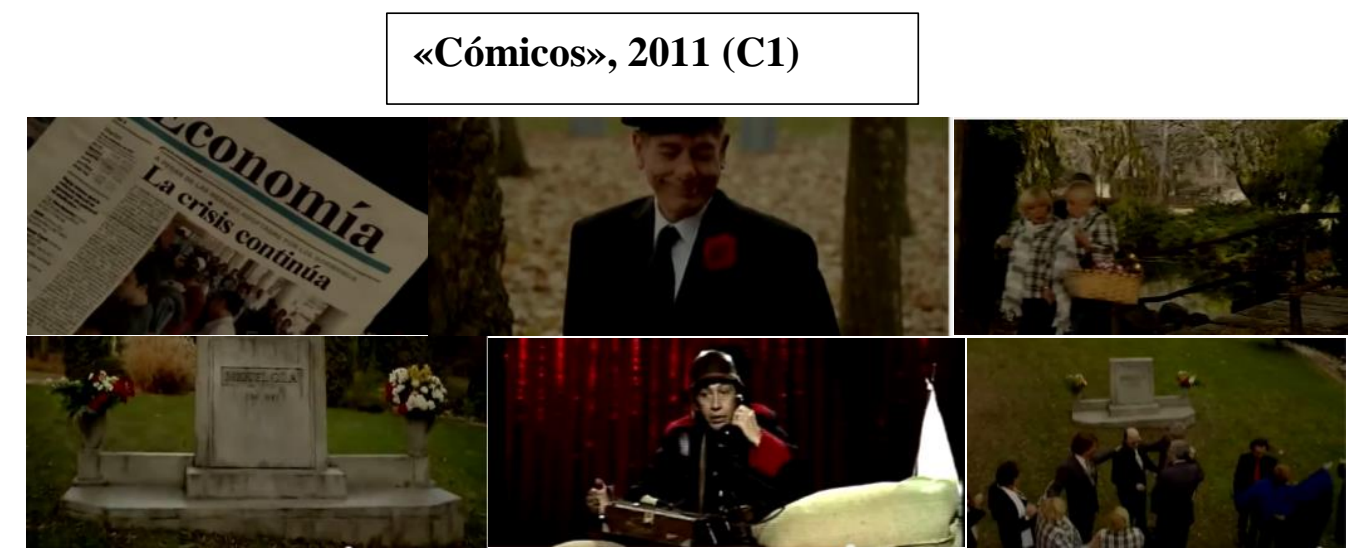

https://www.youtube.com/watch?v=V-83jNawPdk (5/11/14) 


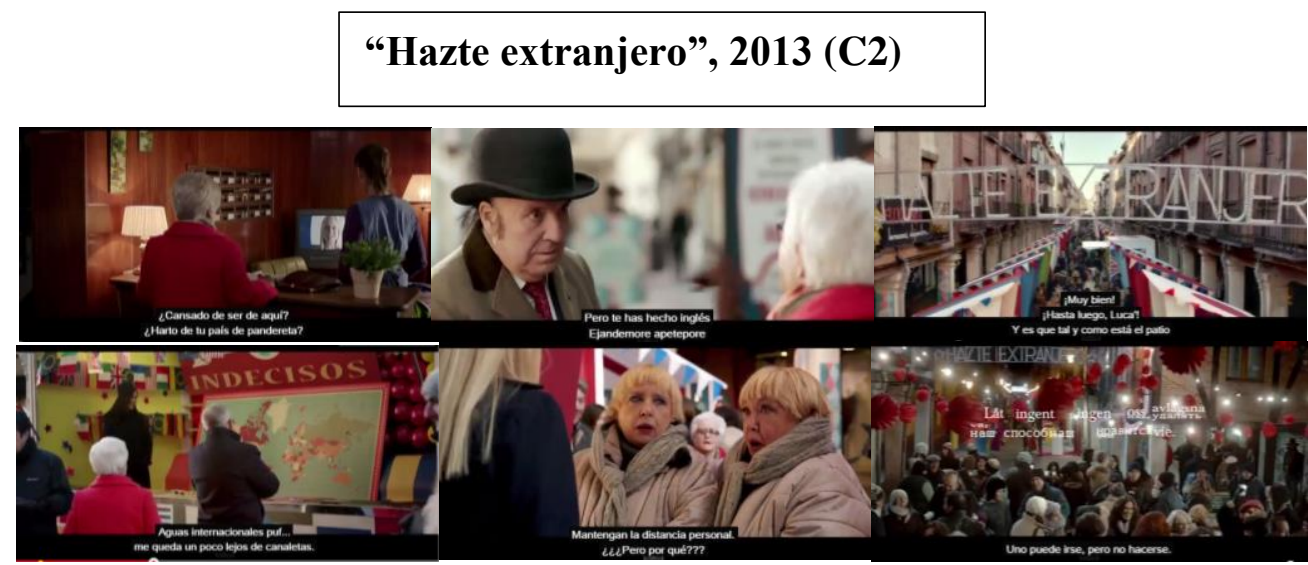

https://www.youtube.com/watch?v=qswkQuMyjPI (5/11/14)

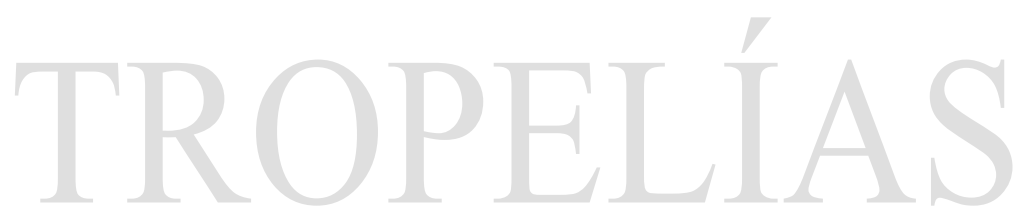

